See Article page 73 .

\section{Commentary: Out with the flow}

\author{
Kristen Errico, MD, and Dawn S. Hui, MD
}

Coronary aneurysms are rare and often present a challenging management dilemma due to their low prevalence, poorly understood etiology, and lack of consensus on management given the paucity of data. Vo and colleagues ${ }^{1}$ present an even rarer clinical conundrum: Giant coronary artery aneurysms (GCAAs). For this entity, the complications of thrombosis/embolization, rupture, compression, and fistula formation can lead to insidious sequale such as myocardial ischemia and heart failure, or more acute presentations such as tamponade. As such, it becomes clear that treatment is warranted. ${ }^{1,2}$

The goals of intervention are to eliminate aneurysm filling as well as prevent distal embolic events. Along with medical and percutaneous treatment options, surgery may include aneurysm ligation, resection, marsupialization, with interposition graft, and/or coronary artery bypass grafting. ${ }^{2-4}$ When planning the surgical approach, one must consider both the inflow and outflow of the involved vessel. In the report by Vo and colleagues, ${ }^{1}$ the additional condition of proximal left anterior descending artery (LAD) stenosis is an important factor. Their operative approach - patch occlusion of the left main ostium and distal ligation of the LAD aneurysm-eliminates the distal embolization pathway and removes native inflow from the left main coronary, but leaves potential for retrograde flow from the circumflex system. In this particular case, the native flow-limiting proximal LAD stenosis is a key factor in restricting continued flow into the aneurysm from the sequentialed arterial bypass of the circumflex system.

\footnotetext{
From the Department of Cardiothoracic Surgery, Joe R. and Teresa Lozano Long School of Medicine, University of Texas Health Science Center at San Antonio, San Antonio, Tex.

Disclosures: The authors reported no conflicts of interest.

The Journal policy requires editors and reviewers to disclose conflicts of interest and to decline handling or reviewing manuscripts for which they may have a conflict of interest. The editors and reviewers of this article have no conflicts of interest.

Received for publication June 21, 2021; revisions received June 21, 2021; accepted for publication June 28, 2021; available ahead of print July 1, 2021.

Address for reprints: Dawn S. Hui, MD, Department of Cardiothoracic Surgery, University of Texas Health Science Center at San Antonio, 7703 Floyd Curl Dr, San Antonio, TX 78258 (E-mail: dawn.hui@gmail.com).

JTCVS Techniques 2021;9:78-9

2666-2507

Copyright (C) 2021 The Author(s). Published by Elsevier Inc. on behalf of The American Association for Thoracic Surgery. This is an open access article under the CC BY-NC-ND license (http://creativecommons.org/licenses/by-nc-nd/4.0/). https://doi.org/10.1016/j.xjtc.2021.06.034
}

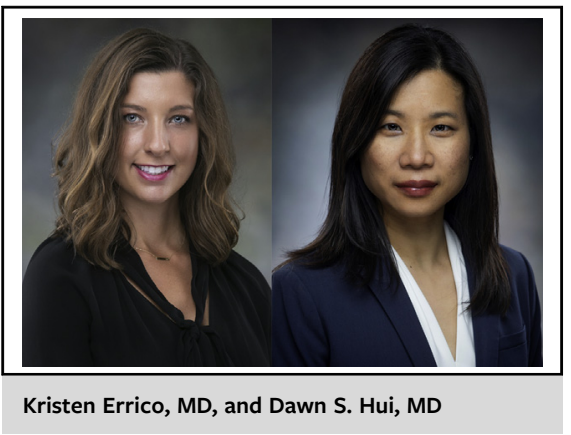

CENTRAL MESSAGE

Although giant coronary artery

aneurysms are rare, complica-

tions can be life-threatening. In

cases of anatomic complexity,

treatment demands an innova-

tive approach to eliminate

endotension.

Whether complete exclusion of flow and elimination of endotension are necessary can be debated. Rupture of coronary artery aneurysms appears to be mostly described in the setting of acute Kawasaki disease, rather than in older adults. ${ }^{5}$ Conversly, in GCCA, both late rupture and mechanical complications such as fistulae have been described. ${ }^{6,7}$ At $5.5 \times 4.8 \mathrm{~cm}$, one could argue that complete exclusion of aneurysmal flow may be important to prevent these mechanical complications. Given the authors' choice to proceed with all arterial grafting, one could infer that the patient's life expectancy is significant. As such, there is likely time for incompletely excluded aneurysms to present future problems. This is supported by the computed tomography angiography obtained at 3 months postoperatively demonstrating subtotal thrombosis; a late follow-up scan demonstrating complete thrombosis would have been more reassuring as to the risk of continued aneurysm growth and potential sequelae. Finally, the third factor in this case is the patient's age. All-arterial grafting will likely provide a definitive treatment in this elderly patient, but in younger patients, future coronary access must be a consideration.

Management of GCAA is not straightforward and we commend the authors for taking a tailored approach to avoid surgical risk. However, there are other approaches that more definitively treat aneurysm. Open exploration, removal of thrombus, and aneurysm exclusion either by resection ${ }^{6}$ or by suture ligation of both inflow and outflow, ${ }^{7}$ have been 
described with good results despite the perceived surgical risk. For aneurysms located in challenging locations, a hybrid approach has been described involving stent deployment across the aneurysm, proximal ligation of any inflow, and distal coronary bypass. ${ }^{8}$ These alternative approaches, providing complete aneurysm exclusion, may protect against complications and are essential in GCAA management.

\section{References}

1. Vo TX, Chin Ngu JM, Glineur D. Total arterial coronary artery bypass grafting of multiple coronary aneurysms. J Thorac Cardiovasc Surg Tech. 2021;9:73-7.

2. Pham V, de Hemptinne Q, Duboc D, Varenne O, Picard F. Giant coronary aneurysms, from diagnosis to treatment: a literature review. Arch Cardiovasc Dis. 2020;113:59-69.
3. Li D, Wu Q, Sun L, Song Y, Wang W, Pan S, et al. Surgical treatment of giant coronary artery aneurysm. J Thorac Cardiovasc Surg. 2005;130:817-21.

4. De Hous N, Haine S, Oortman R, Laga S. Alternative approach for the surgical treatment of left main coronary artery aneurysm. Ann Thorac Surg. 2019;108: e91-3.

5. Miyamoto T, Ikeda K, Ishii Y, Kobayashi T. Rupture of a coronary artery aneurysm in Kawasaki disease: a rare case and review of the literature for the past 15 years. $J$ Thorac Cardiovasc Surg. 2014;147:e67-9.

6. Saxena P, Konstantinov IE, Burstow D, Tam R. Surgical repair of a large coronary artery aneurysm with arteriovenous fistula. J Thorac Cardiovasc Surg. 2006;131: 1167-8.

7. Shomura Y, Mizumoto T, Fujinaga K, Sawada Y, Ito H, Teranishi S. Cardiac tamponade due to rupture of a giant coronary artery aneurysm with a coronary arteriovenous fistula: a case report. Surg Case Rep. 2019;5:40.

8. Bhamidipati CM, McCabe JM, Jones TK, Lombardi WL, Reisman M, Pal JD Hybrid management of a giant left main coronary artery aneurysm. Ann Thorac Surg. 2017;103:e89. 